\section{Questión}

Periodismo / Comunicación ISSN 1669-6581
- Av. $44 \mathrm{~N}^{\circ} 676,1^{\circ}$ piso

CP 1900 - La Plata - Argentina

www.perio.unlp.edu.ar/question

\title{
Los abusos sexuales sobre los niños, aún en la Pandemia.
}

\section{Sexual abuse of children, still in the Pandemic.}

\begin{abstract}
Julieta Añazco iglesias.sin.abusos@outlook.com.ar Activista y sobreviviente de abuso sexual en el ámbito familiar y en el ámbito religioso. Miembro de Iglesias Sin AbuSOS, La Plata. Miembro fundadora de la Red de Sobrevivientes de abuso sexual Eclesiástico de Argentina.
\end{abstract}

\author{
Palabras clave \\ Abuso - Sexual - Niños - Pandemia
}

\section{Keywords}

Abuse - Sexual - Children - Pandemic

La mayoría de los abusos en la niñez se da en los propios hogares de los niños. Las y los abusadores son personas del entorno cercano al niño y en la mayoría de los casos son personas que el niño conoce y confía. Como por ejemplo padres, padrastros, primos, tíos, hermanos, amigos familiares, la niñera, el médico pediatra, la monja, el sacerdote, la o el Docente, etc. Los abusos pueden darse por las noches, mientras la madre del niño duerme. No es necesario que el abusador esté a solas con el niño, en mi caso hay una foto familiar en dónde el que era mi tío, está por debajo del agua, tocando mis partes íntimas en una pileta en verano, y en la misma pileta había más gente, de hecho, está la foto, pero no se ve bien, yo lo sé porque lo viví. No necesitan demasiado tiempo para atacar a un niño. El abuso sexual es el Delito menos denunciado y más silenciado. Ya que cuando los abusos sexuales se producen en la niñez, en su mayoría, los abusadores inculcan la idea del "SECRETO", que lo que allí sucede debe ser guardado como un secreto, y que no deben contarlo a nadie, en otras ocasiones el abusador le inculca al niño la idea de que lo que allí está sucediendo, es un juego. En otras ocasiones 
amenazan de muerte a la familia del niño. En muchas ocasiones es tan grande el miedo que esos ataques nos generan, que nos paraliza dejándonos imposibilitados de hablar, no podemos poner en palabras el ataque al cual fuimos sometidos. En otras situaciones nuestra mente bloquea esos recuerdos, como mecanismo de defensa para no sufrir. Y con mucha suerte un día tenemos un disparador (en mi caso fue el nacimiento de mi nieto), que hace que esos recuerdos "olvidados", vengan a nuestra memoria, quedándonos sin poder parar su flujo. Una vez que comienzan a venir a nuestra mente no hay manera de pararlos, por eso es tan alto el porcentaje de suicidios de víctimas de abuso sexual. Porque una vez que pudimos develar ese secreto y pudimos ponerlo en palabras y descubrimos que lo que nos pasó fue abuso sexual, muchas veces el estrés post traumático hace que nuestro cuerpo enferme. Nuestro cuerpo empieza a hablar, al parecer volvemos a revivir el dolor que padecimos aquella vez, porque no lo supimos expresar. Por ello es por lo que muchas veces tardamos muchos años en poder poner en palabras lo que nos pasó. Por ello es por lo que hablamos cuando podemos, no cuando queremos. Y cuando al fin podemos romper el silencio que nos impusieron las personas que nos atacaron sexualmente, cuando por fin podemos prepararnos psicológica, psiquiátrica y legalmente, llegamos a la Justicia queriendo denunciar a las personas que nos atacaron, y en la Justicia nos dicen que las causas prescriben, que tienen fecha de vencimiento. La "prescripción" de una causa significa que como pasaron muchos años de los hechos, no se nos permite denunciar. Nuestro dolor y nuestras secuelas No Prescriben, nos acompañan y acompañarán toda la vida, es y será nuestro trabajo aprender a vivir con todo aquello y esto. En muchos casos muchas víctimas quedan y quedarán en el camino, muchos se suicidarán, otros caerán en algún tipo de adicción para intentar parar nuestras cabezas y nuestros recuerdos. En muchos casos queremos acceder a la Justicia siendo adultos y como tales, lo que nos preocupa es la protección de los niños y adolescentes vulnerables que puedan estar cerca de las personas que nosotros denunciamos. Porque sabemos que los abusadores no son enfermos, no se recuperan, atacarán sexualmente toda su vida. Por todo lo expuesto es necesario que sepan que nosotros no fabulamos. En mi caso, tenía un nieto de 5 meses al cuál disfrutar plenamente y no pude, porque me atravesaron los recuerdos padecidos en mi infancia y a partir de allí comenzó el camino de búsqueda de Verdad, Reparación y Justicia. El camino de la denuncia muchas veces es un camino revictimizante, el desgaste es emocional, corporal y psicológico. 
Pedimos a los Operadores Judiciales que apliquen la Ley de Respeto a los Tiempos de las Víctimas (Ley 27206, sancionada en el año 2015 por impulso de la Senadora Sigrid Kunath, de Paraná, Entre Ríos), así como lo hicieron los Juzgados en Paraná y en Resistencia (Chaco). Lamentablemente aún existe un vacío legal para algunos sobrevivientes y no se nos permite nuestro derecho de poder acceder a la Justicia. Por ello es por lo que impulsamos a nivel Nacional la Campaña Contra la Prescripción de los delitos de violencia sexual. Dicha Organización está compuesta por mujeres adultas que hemos sufrido abusos sexuales en nuestra infancia y luchamos para que el Código Penal sea reformado, y así podamos tener todos los sobrevivientes de este delito atroz, derecho a la Justicia.

Pedimos a la sociedad que tome nuestra lucha, la protección de la infancia, y que presten atención a los siguientes indicadores: los cambios bruscos de conducta, a los juegos, a los dibujos, a las pesadillas, muchos niños suelen sufrir enduresis o encopresis (no controlan los esfínteres), a la ansiedad, insomnio, autolesiones y en el peor de los casos a los intentos de suicidio.

Es importante que se garanticen políticas públicas de capacitación a niños, adolescentes, jóvenes, padres, madres, a Profesionales y a los Operadores Judiciales y a la sociedad en general. Las capacitaciones muchas veces no son accesibles para todos debido al alto costo. Se entiende perfectamente que es un trabajo y que, en casos de fundaciones autónomas y no gubernamentales, se necesita del capital para sostenerlas. Pero también se precisa llegar a las personas de las formas que sean posibles con un lenguaje claro y no técnico. Es tarea tanto de profesionales como de activistas y sobre todo del Estado el facilitar la información y un trato empático para con las personas ante un tema tan complejo.

Un informe estadístico reciente del Programa Las Víctimas contra las Violencias del Ministerio de Justicia y Derechos Humanos de la Nación mostró que el hogar es el lugar donde más frecuentemente se registran los casos de agresiones sexuales denunciados en sus líneas de atención, con un porcentaje del $46 \%$. Además, el $57 \%$ de los abusadores son varones de la familia y 8 de cada 10 víctimas de abuso sexual infantil son nenas.

Porque

\#Los Niños No mienten, los abusadores, sí.

\#YoSiTeCreo 